\title{
Testicular seminoma in a patient with pineal germinoma
}

\author{
D S Peat, J E Trowell
}

\begin{abstract}
$A$ case is reported of a 30 year old man with a testicular seminoma. He had presented 16 years previously with a pineal germinoma, followed two years later by intracranial metastases. This is an unusual occurrence of double pathology in the germ cell line.
\end{abstract}

$(f$ Clin Pathol 1994;47:771-772)

\section{Case report}

A 30 year old man presented with a four month history of a swollen left testis. Examination showed that the testis was hard and irregular. A left orchidectomy was subsequently performed. Macroscopically, the testis was enlarged to $7 \mathrm{~cm}$ maximum diameter and replaced by a $5 \mathrm{~cm}$ white tumour containing foci of necrosis and haemorrhage. Histological examination showed a testicular seminoma (fig 1A) invading through the testicular capsule into the epididymis. The tumour was focally necrotic with no trophoblast or yolk sac elements. In situ seminoma was not identified in the few remaining seminiferous tubules.

The patient had a long history dating back to 1977 , when, aged 14 , he developed hydrocephalus from a pineal tumour. The hydrocephalus was treated with a ventriculo-atrial shunt, and radiotherapy was given to the anterior cranium for one month. This tumour was never biopsied. Two years later he developed a right hemiparesis and metastases were found in the left posterior parietal region. These were treated by excision biopsy followed by radiotherapy to the whole brain and spinal cord. A computed tomography head scan in 1985 suggested the presence of metastases in the Sylvian fissure. Since then he has continued to have right-sided pain, thought to be due to thalamic invasion by the tumour, with a slow deterioration in general condition, occasional fits, an unsteady gait, slurred speech and optic atrophy. The $\beta$ subunit of human chorionic gonadotrophin, $a$-fetoprotein and placental alkaline phosphatase activities have remained within normal limits and chest radiographs have been normal.

The biopsy of the parietal mass in 1979 comprised irregular, mottled grey tissue with haemorrhagic areas, infiltrating the dura mater. Histological examination showed a germinoma with syncitiotrophoblast-like cells and many mitoses (fig 1B), consistent with a metastasis from the presumed pineal germinoma.

\section{Discussion}

Neoplasms of the pineal gland are rare, accounting for $0.4-1 \%$ of intracranial tumours. The most common are germinomas-germ cell tumours with pluripotential differentiation capabilities. Their prevalence
Department of Histopathology, Ipswich Hospital, Heath Road, Ipswich IP4 5PD

D S Peat

J E Trowell

Correspondence to: Dr D S Peat

Accepted for publication 9 February 1994
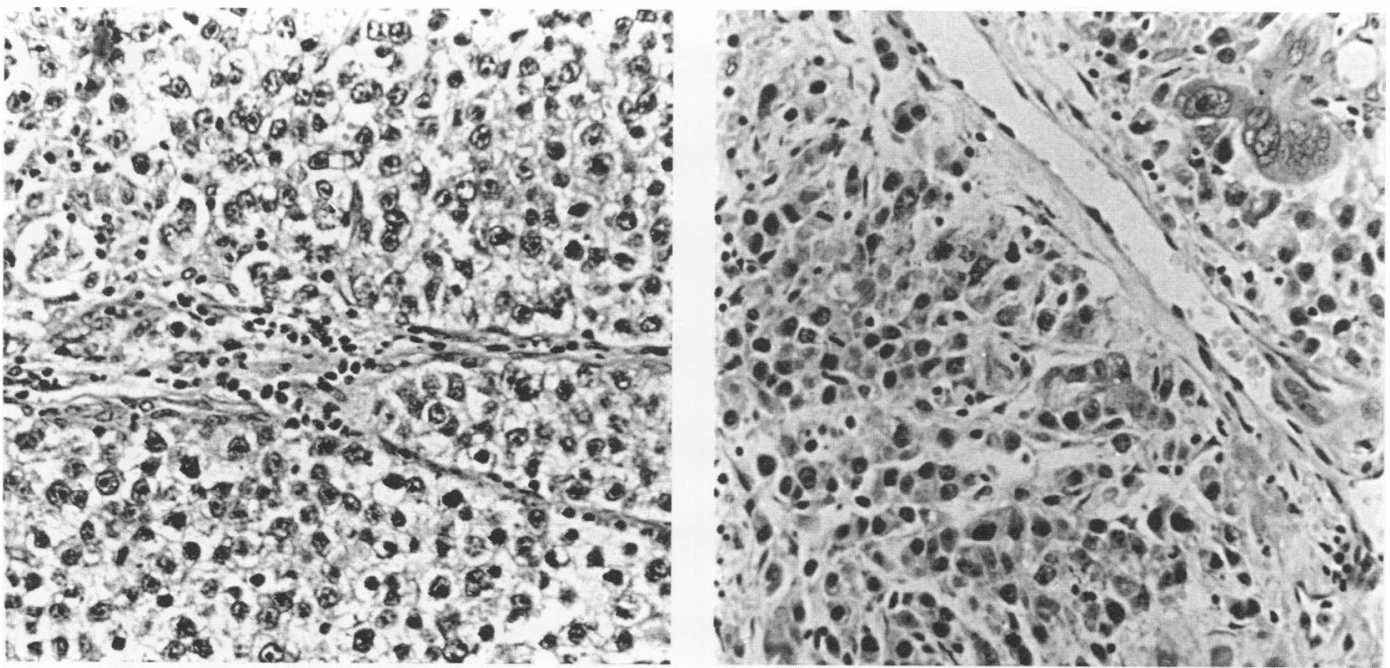

Figure (A) Testicular seminoma. Regular clear polyhedral cells are separated by fibrous bands infiltrated with lymphocytes. Mitoses are not seen. (B) Pineal germinoma with groups of syncitiotrophoblast-like cells. 
is higher in men. The pineal and parapineal regions are the commonest sites of intracranial germinomas, but there have been reports of primary germinomas in the third and fourth ventricles and the cerebellar and occipital cortex. Germ cell tumours can also occur in the midline outside the central nervous system in the anterior mediastinum ${ }^{1}$ and retroperitoneum. This is thought to be a result of neoplastic transformation of migrating primitive germ cells which failed to reach the urogenital ridge and remained in midline structures.

Metastatic infiltration of the ventricular system and spinal meninges is the commonest mode of spread occurring in $7-12 \%$ of cases. ${ }^{2}$ Systemic metastases are rare. Intraperitoneal deposits have been reported from a ventriculoperitoneal shunt ${ }^{3}$ and there are a few cases of haematogenous metastases to the lungs, liver, and rarely, bone. ${ }^{4}$ Spread to lumbar musculature, presumably through lumbar vertebral foramina has also been described. ${ }^{5}$ Metastases to the testes have not been reported.

In our opinion the testicular tumour in this case report represents a second primary germ cell tumour. The long time interval of 16 years makes it highly unlikely that the original pineal tumour was a metastasis from the present seminoma. Intracranial metastases from a pure seminoma have not been reported before, and when malignant teratomatous and trophoblastic testicular tumours metastasised these were preceded by, or coincided with, pulmonary metastases. ${ }^{6}$ It is also unlikely that a distant testicular metastasis occurred from a primary intracranial germinoma as no other extracranial metastases were evident in our patient.

There have been several reports of germ cell tumours occurring in more than one site in the same patient. Testicular germ cell tumours can be bilateral in $1 \cdot 1-2 \cdot 7 \%$ of cases, rising to $15 \%$ in undescended testes. ${ }^{7}$ These are most often classic or spermatocytic seminomas. Associations between pineal germinomas and non-gonadal germ cell tumours have been reported: a hypothalamic teratoma occurred in a 20 year old man with a concurrent malignant teratoma of the anterior mediastinum, ${ }^{8}$ and a suprasellar germinoma coexisted with a dermoid cyst of the pineal gland. ${ }^{9}$ We have found only one other report ${ }^{10}$ similar to ours, in a 23 year old man who developed a seminoma five years after a pineal germinoma. He had no regional or distant metastases.

In summary, as far as we are aware, this is only the second case of a gonadal seminoma occurring several years after a pineal germinoma. The occurrence of two primary germ cell tumours in one patient may represent a mutation in the germ cell line.

Our thanks to Dr Scaravilli, National Institute of Neurology, London, for supplying the slides from the previous intracranial tumour.

1 Cox JD. Primary malignant germinal tumors of the mediastinum - a study of 24 cases. Cancer 1975;36:1162-8.

2 Russell DS, Rubinstein LJ. Pathology of tumours of the nervous system. London: Edward Arnold, 1989.

3 Haimovic IC, Sharer L, Hyman RA, Beresford HR. Metastasis of intracranial germinoma through a ventricular peritoneal shunt. Cancer 1981;48:1033-6.

4 Levin CV, Rutherford GS. Metastasizing pineal germinoma-a case report and review. South Afr Med $f$ 1985;68:36-9.

5 Rubery ED, Wheeler TK. Metastases outside the central nervous system from a presumed pineal germinoma. $\mathcal{f}$ Neurosurg 1980;53:562-5.

6 Vugrin D, Cvitkovic E, Posner J, Hajdu S, Golbey RB Neurological complications of malignant germ cell tumours of the testis. Biology of brain metastases (I) Cancer 1979;44:2349-53.

7 Kristianslund S, Fossa SD, Kjellevold K. Bilateral malig nant testicular germ cell cancer. Br f Urol 1986;58:60-3.

8 Dayan AD, Marshall AHE, Miller AA, Pick FJ, Rankin NE. Atypical teratomas of the pineal gland and hypothalamus. $\mathcal{F}$ Pathol Bacteriol 1966;92:1-28.

9 Russell DS. The pinealoma: its relationship to teratoma. 7 Pathol Bacteriol 1944;56:145-50.

10 Trentini GP, Maiorana A, De Benedittis A. Metachronous seminoma of the pineal region and right testis. Appl Pathol 1985;3:129-33. 